Sahlgrenska Hospital, Gothenburg, Sweden $M$ Andersson

Hospital Ramon y Cajal, Madrid, Spain J Alvarez-Cermeño

Instituto Nationale Neurologico "C.

Besta", Milan, Italy

G Bernardi

Ospedale Civile, Fidenza, Parma, Italy I Cogato

Mölndal Hospital, Mölndal, Sweden $P$ Fredman

Gentofte Hospital, Copenhagen, Denmark J Frederiksen

Karolinska Institute, Huddinge, Sweden $S$ Fredrikson

Institute of Neurology, Padua, Italy

P Gallo

San Raffaele Hospital, Milan, Italy

L M Grimaldi

Institute of Neurology and Neurosurgery, Bergen, Norway M Grønning

Institute of Neurology, London, UK

G Keir

Radboud University Hospital, Nijmegen, The Netherlands

K Lamers

Karolinska Institute, Huddinge, Sweden

H Link

Institute of Neurology, Lisbon, Portugal

A Magalhães

Ospedale Sacro Cuore,

Rome, Italy

A R Massaro

University Hospital, Linköping, Sweden $S$ Öhman

University Neurology

Clinic, Göttingen,

Germany

H Reiber

Sahlgrenska Hospital, Gothenburg, Sweden L Rönnbäck

Centre Hospitalier Universitaire Vaudois, Lausanne, Switzerland $M$ Schluep

Hôpital de la

Salpêtrière, Paris,

France

E Schuller

Catholic University of Louvain, Brussels,

Belgium

C J M Sindic

Institute of Neurology, London, UK

E J Thompson

University Neurology

Clinic, Bari, Italy

M Trojano

\title{
Cerebrospinal fluid in the diagnosis of multiple sclerosis: a consensus report
}

\author{
M Andersson, J Alvarez-Cermeño, G Bernardi, I Cogato, P Fredman, J Frederiksen, \\ S Fredrikson, P Gallo, L M Grimaldi, M Grønning, G Keir, K Lamers, H Link, \\ A Magalhães, A R Massaro, S Öhman, H Reiber, L Rönnbäck, M Schluep, E Schuller,
} C J M Sindic, E J Thompson, M Trojano, U Wurster

\section{Abstract}

The Committee of the European Concerted Action for Multiple Sclerosis (Charcot Foundation) organised five workshops to discuss CSF analytical standards in the diagnosis of multiple sclerosis. This consensus report from 12 European countries summarises the results of those workshops. It is hoped that neurologists will confer with their colleagues in clinical chemistry to arrange the best possible local practice. The most sensitive method for the detection of oligoclonal immunoglobulin bands is isoelectric focusing. The same amounts of IgG in parallel CSF and serum samples are used and oligoclonal bands are revealed with IgG specific antibody staining. All laboratories performing isoelectric focusing should check their technique at least annually using "blind" standards for the five different CSF and serum patterns. Quantitative measurements of IgG production in the CNS are less sensitive than isoelectric focusing. The preferred method for detection of blood-CSF barrier dysfunction is the albumin quotient. The CSF albumin or total protein concentrations are less satisfactory. These results must be interpreted with reference to the age of the patient and the local method of determination. Cells should be counted. The normal value is no more than 4 cells/ $\mu 1$. Among evolving optional tests, measurement of the combined local synthesis of antibodies against measles, rubella, and/or varicella zoster could represent a significant advance if it offers higher specificity (not sensitivity) for identifying chronic rather than acute inflammation. Other tests that may have useful correlations with clinical indices include those for oligoclonal free light chains, IgM, IgA, or myelin basic protein concentrations.

$(\mathcal{F}$ Neurol Neurosurg Psychiatry 1994;57:897-902)

The clinical diagnosis of multiple sclerosis can be supported by the use of laboratory techniques for the analysis of CSF. This important fact has already been acknow- ledged by another group of experts. ${ }^{1}$ We have refined their notions of "oligoclonal bands or increased CNS production of IgG" and offer considered opinions on the relative importance of different approaches to the study of CSF immunoglobulins. Specifically, we have contrasted qualitative (oligoclonal bands) with quantitative (increased CNS production of IgG) methods for their sensitivity and specificity (defined later) in the diagnosis of multiple sclerosis.

There are, unfortunately, several papers on multiple sclerosis that do not give sufficient technical details of the methods used for the determination of oligoclonal bands or increased CNS production of IgG. These techniques must clearly be calibrated by each individual laboratory. To allow proper international comparisons, authors should specify what percentage of patients with clinically definite multiple sclerosis are positive with their techniques-that is, the test sensitivity. They should also state what percentage of normal or other inflammatory diseases (acute or chronic) are positive-that is, the test specificity. These are important because the percentage will be influenced by the local prevalence of multiple sclerosis and other inflammatory diseases.

There is a voluminous literature on CSF analysis in multiple sclerosis ranging from more fundamental aspects to reported changes with treatment. We thus refer to some selected reviews. ${ }^{2-9}$ What is of more practical relevance to the neurologist is the role of CSF analysis in helping to make the diagnosis of multiple sclerosis.

Approach to consensus on single topics Delegates were chosen from most European countries with an inclination towards those who had provided a laboratory diagnostic service by CSF analysis. The topics discussed were initially assigned to individual delegates who each prepared a discussion paper on their respective topic of interest. It was also agreed that the relative importance of each recommendation would be assigned to one of three categories of tests: (1) an Essential test is required to support the laboratory basis for diagnosis of multiple sclerosis; (2) Complementary tests provide useful additional information to further support the diagnosis, 
Medical School, Hannover, Germany U Wurster

Correspondence to: Professor E J Thompson, Institute of Neurology, Institute of Neurology, WCIN 3BG, UK. Received 16 July 1993 and in final revised form 19 January 1994.

Accepted 25 January 1994
Frequencies of abnormal CSF variables in clinically definite multiple sclerosis

\begin{tabular}{ll}
\hline Essential test: & \\
$\begin{array}{l}\text { Oligoclonal IgG in CSF (isoelectric focusing) } \\
\text { Complementary tests: }\end{array}$ & $>95 \%$ \\
$\begin{array}{l}\text { Abnormal blood CSF barrier function } \\
\quad\left(\mathrm{QAlb}>7 \times 10^{-3}\right)\end{array}$ & $12 \%$ \\
$\begin{array}{l}\text { Increased IgG quotient (IgG index, IgG (local)) } \\
\text { Increased cell count }>4 / \mu \mathrm{l}\end{array}$ & $\begin{array}{l}70-80 \% \\
50 \%\end{array}$ \\
\hline
\end{tabular}

and (3) Optional tests are used in some local centres to provide additional information. Further work on the optional tests is being undertaken, however, to try to establish their eventual role in aiding diagnosis.

In practical terms we worked through three sequential drafts with each version becoming successively shorter. The principle of consensus then adopted was that if more than two people objected, the relevant statement was dropped. It was not difficult to agree unanimously on isoelectric focusing but there were obvious objections to the use of any one reference as the "chosen" technique. After much discussion about blood-brain and CSF barriers and mathematical formulations that attempt to express quantitative measures of "CNS production of IgG", all agreed that these were not essential (as opposed to isoelectric focusing). There was, however, almost unanimous agreement on non-linear formulations, which in practice would be different in various laboratories. Most other issues were eventually agreed without undue difficulties.

\section{Diagnosis of multiple sclerosis}

The diagnosis of multiple sclerosis is ultimately a clinical decision although examination of CSF among other paraclinical tests is an important guide. Perhaps the greatest attraction of CSF examination is that it can primarily show an inflammatory origin of CNS abnormalities.

Of the various tests that can be applied to CSF, those that detect a humoral immune response within the CNS are the most important in multiple sclerosis. This is because oligoclonal banding of $\mathrm{IgG}$ is reported in most patients with multiple sclerosis. Isoelectric focusing is the most sensitive method for detecting local synthesis when compared with all other quantitative and qualitative methods. Local synthesis is not

Figure 1 CSF IgG index. The $y$ axis shows increasing values for the quotient of IgG in quotient of IgG in the $x$ axis shows increasing values for the quotient of albumin in CSF/albumin in serum. The four areas signify: (1) normal; (2) local synthesis (normal barrier function); (3) local synthesis plus abnormal barrier function; (4) barrier function abnormal (not local synthesis).

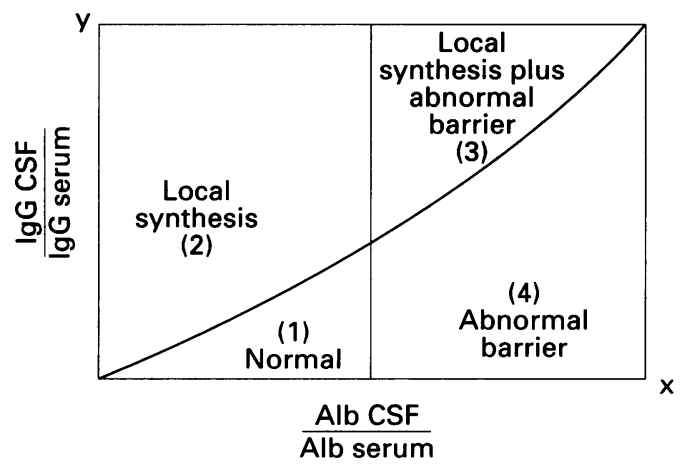

specific to multiple sclerosis, however, as there may be oligoclonal bands of IgG in many other inflammatory neurological diseases. It is considered an essential test, whereas three others are considered complementary (table). Some optional tests are also considered.

\section{Integrated report}

When the results of several tests that can give parallel information are available, these should be presented in a clinically orientated report. The clinician may benefit if some form of quantitative graphical representation (fig 1) is used for such an integrated report. It has to be emphasised that the time of lumbar puncture with respect to the course of the disease is important for the interpretation of CSF data. In arriving at consensus for the graphical representation in fig 1, the following points were noted as showing an overall agreement: Laurell subsequently modified his original plot to show a change in slope rather than a simple straight line. Reiber and Felgenhauer devised an empirical fit to yield a hyperbolic curve, as contradistinct from Reiber's original straight line(s) model. Schuller's terms for the relevant areas are: (2) "inflammatory"; (3) "meningitic"; (4) "transudate". Sindic's term for area (4) is "mirror". Thompson's term for area (3) is "greater than".

\section{Single topics}

SAMPLE HANDLING AND CELL EXAMINATION

A defined amount (about $10 \mathrm{ml}$ in adults, less in children) of CSF should be collected in polypropylene, siliconised glass, or glass tubes to allow for all tests (table). Cell numbers should be counted within 30-60 minutes of lumbar puncture. If the lumbar puncture is not performed at the same hospital as the CSF laboratory, the CSF should be transported to the CSF laboratory as soon as possible (preferably within six hours) for routine cytological examination. Differential cell loss occurs during CSF storage. The number of white cells in normal CSF is no more than $4 / \mu 1 .{ }^{9}$

Cytological examination is considered a complementary test in the diagnosis of multiple sclerosis. About $50 \%$ of patients with clinically definite multiple sclerosis show a normal cell count and only $1 \%$ of patients with multiple sclerosis have cell counts of more than $35 / \mu \mathrm{l}$. Cell counts $>35 / \mu \mathrm{l}$ make multiple sclerosis unlikely, and thus other diagnoses should be considered.

Different methods such as cytocentrifuge or sedimentation chamber can be used for cytological preparation. ${ }^{10}$ The reporting of CSF cytology to the clinician should be descriptive including, if possible, considerations of any alternative diagnosis.

EVALUATION OF THE BLOOD-CSF BARRIER The blood-brain barrier is different from the blood-CSF barrier. By analysing the protein 
content of lumbar CSF, it is possible to assess the integrity of the (functionally defined) blood-CSF barrier, but not the isolated blood-brain barrier. In healthy people or in patients without objective signs of neurological disorders, the passage of plasma proteins across the blood-CSF barrier depends on their hydrodynamic radii, which are related to their molecular weights under steady state conditions. ${ }^{11}$ In such populations the absolute CSF concentrations of specific plasma derived proteins depend on many factors including the serum concentration of each protein, blood-CSF barrier integrity, rate of CSF flow, molecular size of the protein, age of the patient, and the volume of CSF removed.

Albumin, the major CSF protein, is synthesised only by hepatocytes and is not catabolised within the CNS. Dynamic studies with intravenously injected radiolabelled albumin $^{12}$ have shown that serum is the source of CSF albumin and strongly support the use of $\mathrm{CSF} / \mathrm{serum}$ albumin quotients (QAlb = CSF albumin/serum albumin) to assess the blood-CSF barrier function. Another approach ${ }^{1314}$ is related to the measurement of CSF albumin only: any increase of CSF albumin (above the mean) indicates altered blood-CSF barrier function.

Determination of total CSF protein is less reliable than that of CSF albumin. If total protein is adopted as an alternative to albumin, then the method used should yield a similar optical density/g protein for both albu$\mathrm{min}$ and IgG. This is necessary in view of the wide variability of IgG relative to albumin, which can vary between $3 \%$ in normal and $30 \%$ in abnormal CSF. The IgG ratio (CSF $\mathrm{IgG/CSF}$ albumin) is of limited value as a parallel serum specimen should be analysed (see later).

The albumin quotient is age dependent. ${ }^{1516}$ The upper reference limit for the first $10 \mathrm{ml}$ of lumbar fluid is $5.0 \times 10^{-3}$ for patients under 15 years of age; $6.5 \times 10^{-3}$ for patients aged 16-40 years; $8 \times 10^{-3}$ for patients aged $40-60$ years and $8-9 \times 10^{-3}$ for patients over 60 years. Most patients with multiple sclerosis have values for the albumin quotient below the upper reference limit. Higher values suggest a different neurological disorder.

Transudated CSF immunoglobulins, as calculated by a CSF/serum quotient, are not linearly related to the albumin quotient in cases with blood-CSF barrier dysfunction. The use of non-linear formulae or graphs for the interpretation of $\mathrm{IgG}$ values is therefore recommended (fig 1).

To minimise analytical imprecision, the CSF and serum concentrations for each particular protein should be analysed by the same method and within the same analytical series.

QUANTIFICATION OF THE HUMORAL IMMUNE RESPONSE IN THE BRAIN

It is a necessary requirement for any quantitative assay that each laboratory must establish its own reference range for particular protein tests.

The detection of a humoral immune response in the CNS requires an expression of results that will discriminate between blood derived and brain derived immunoglobulin fractions in CSF. Such quantitative expressions are based on calculations of the CSF/serum quotients. ${ }^{121417-19}$ These quotients are also used for comparisons of intrathecal synthesis of all immunoglobulin classes (IgG, IgA, IgM), as well as quantitative follow up of intrathecal antibody synthesis, and calculation of specific antibody index values (also called antibody specific activity).

Use of the CSF/serum quotient for IgG reduces variation due to differences in the individual concentrations of serum IgG. By referring this CSF/serum IgG quotient to the $\mathrm{CSF} /$ serum albumin quotient it is possible to further reduce the variation of the IgG quotient related to individual differences in blood-CSF barrier function. There are many approaches by which both of these quotients are combined to obtain an expression that will discriminate between the locally synthesised IgG fraction in the brain and the fraction of CSF IgG that is derived from the blood by filtration.

The use of a non-linear relation between the IgG quotient and the albumin quotient is recommended, as a linear approach can lead to a loss of sensitivity when there is bloodCSF barrier dysfunction. ${ }^{19-22}$ This is especially true for larger molecules such as IgA or IgM. If quantitative values are reported, the graphical representation of the immunoglobulin quotients (fig 1) as a function of the albumin quotient is recommended as this gives simultaneous information about any local humoral immune response or any blood-CSF barrier dysfunctions. Measurements of $\operatorname{IgM}$ and IgA indices are optional tests currently under study to investigate whether they provide additional useful information. ${ }^{14} 23$

Another optional test under study is the detection of intrathecal synthesis of specific antibodies (for instance, against the measles virus). These specific antibody tests have gained further clinical relevance through improvement of the sensitivity of the evaluation techniques, mainly by the introduction of extrapolation methods for the locally synthesised fraction of IgG (or $\operatorname{IgM}$ ), as well as correction for any blood-CSF barrier dysfunction. ${ }^{14}{ }^{24-26}$ Of special interest for the diagnosis of multiple sclerosis is the report that polyspecific antibody synthesis against several different viruses can occur in the brain. In one series, local synthesis of antibody to measles, rubella, and/or zoster could be found in the CSF of $94 \%$ of patients with multiple sclerosis. ${ }^{26}$ The relevance of these methods has been partially confirmed by the identification of oligoclonal patterns on isoelectric focusing for each virus (measles, rubella, zoster) by use of the affinity mediated capillary blot technique. ${ }^{27}$ Also, it has been found 


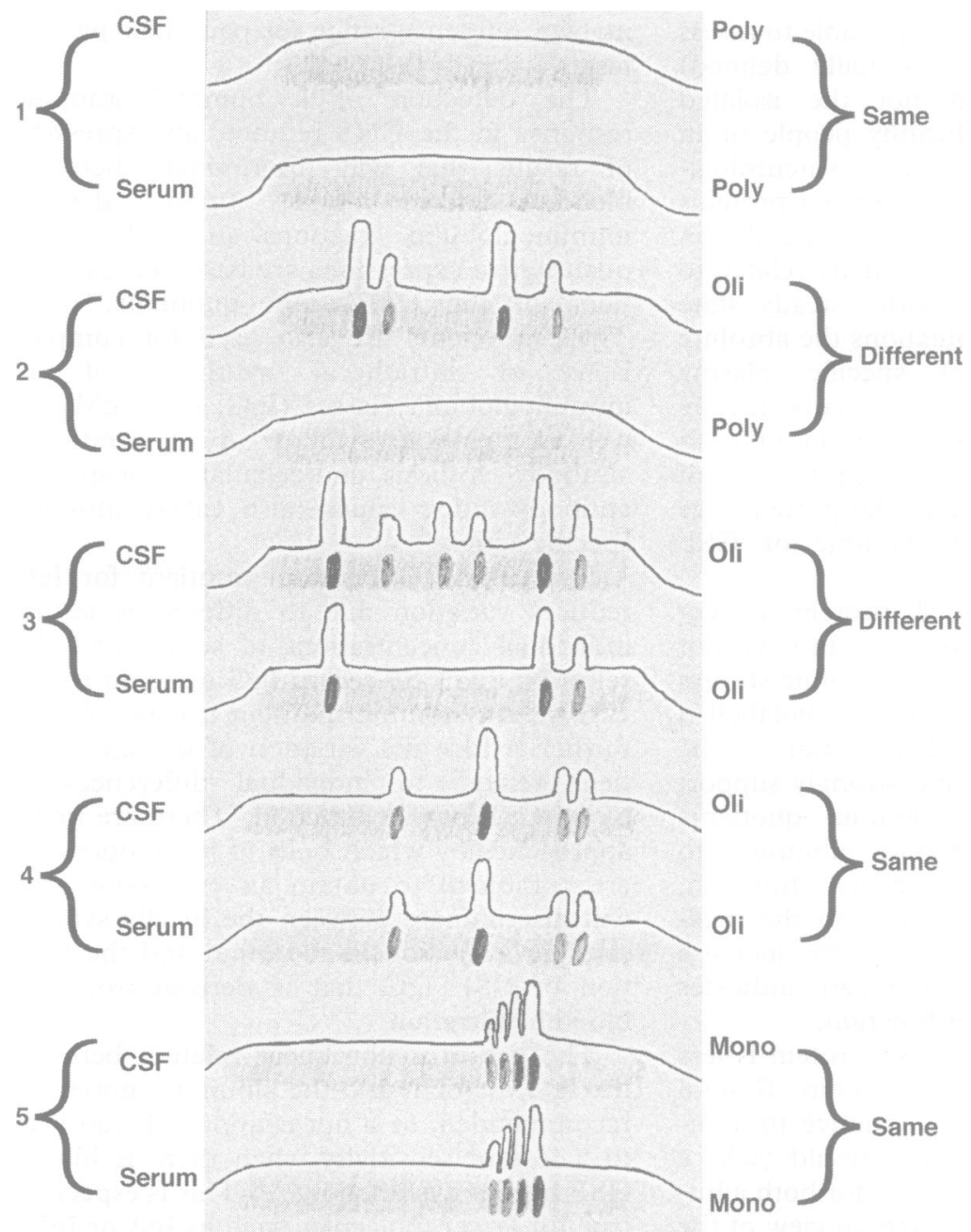

Figure 2 Diagram showing idealised CSF and serum isoelectric focusing patterns. Different CSF/serum patterns denote local IgG synthesis. Densitometric scans of the patterns show the differences in optical density (relative amounts of protein per band). Type 1 is normal. Type 2 is found in multiple sclerosis. Type 3 is found in multiple sclerosis and brain inflammation in systemic disease-for example, sarcoidosis. Type 4 is found in systemic inflammation-for example, Guillain-Barre syndrome. Type 5 is found in myeloma or monoclonal gammopathy of uncertain significance; The $p H$ gradient is from $6-9$ and the cathode is on the right; Poly = polyclonal; Oli = oligoclonal; Mono = monoclonal.

Figure 3 CSF and serum isoelectric focusing patterns. Different CSF/serum patterns denote local IgG synthesis. Typical examples of the five patterns shown in fig 2. Details are the same (see legend to fig 2).
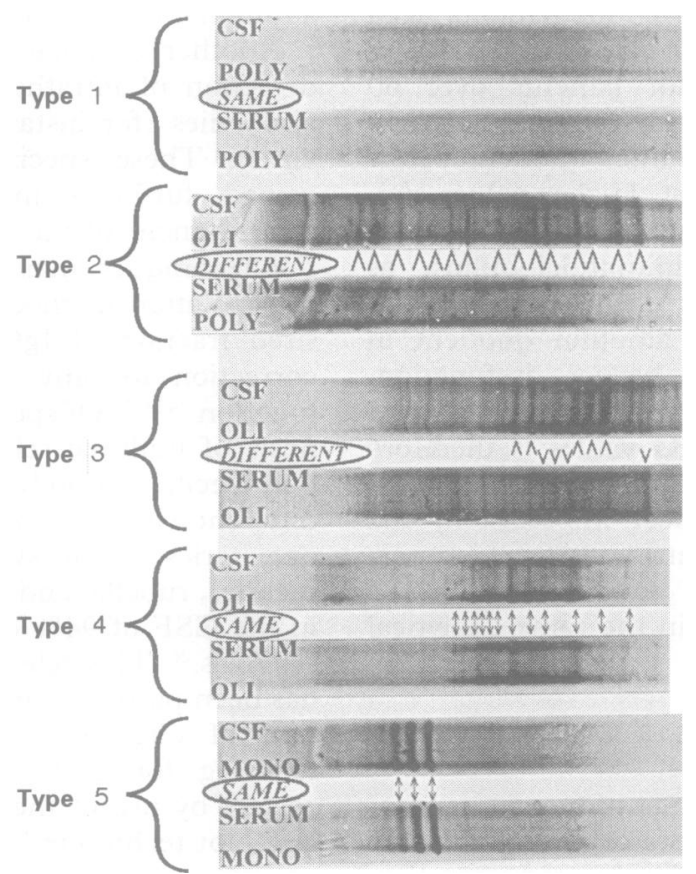

that the antibody affinity is different in acute compared with chronic diseases, which further supports the idea that the polyspecific immune response may also become an important tool for diagnosis in multiple sclerosis. ${ }^{28}$

For the correct interpretation of the humoral immune response in CSF, it is important to keep in mind that the local IgG, IgA, or IgM synthesis, including any specific antibody synthesis in the brain, might have several origins. It could be due either to a persistent antibody response from an old clinically irrelevant immunological process or to an acute inflammatory process. Local IgG synthesis, detected either by increased IgG quotients, formulae, or by isoelectric focusing, can still be seen many years after adequately treated cases of neurosyphilis or neuroborreliosis, among other examples of an intrathecal immune response.

ISOELECTRIC FOCUSING OF OLIGOCLONAL IgG The strongest consensus is that isoelectric focusing is the most sensitive test for the detection of humoral immune responses when using the same amounts of IgG in parallel CSF and serum specimens. ${ }^{13} 212729-39$ The oligoclonal bands resolved are preferably visualised by IgG specific antibody staining. Also, useful information can be obtained concerning other proteins by means of a general protein stain.

It should be emphasised that the finding of oligoclonal bands by isoelectric focusing is not specific for multiple sclerosis. It reaches its maximal value in differential diagnosis only when other known causes of CNS inflammation have been excluded.

The significance of individual bands in CSF can only be properly understood in the context of a parallel serum specimen as well as attention to the overall band pattern of all sample tracks on the isoelectric focusing plate. Isoelectric focusing can be simply thought of as separation of IgG on the basis of different charges or isoelectric points. It is important to exclude artefactual bands that are caused by non-linearity of the isoelectric focusing $\mathrm{pH}$ gradient. A good practical indicator for these is to compare the serum patterns from several patients. Bands that are at the same isoelectric point in all specimens of a given run are most likely to be artefacts produced by the ampholytes used in the separation. The higher the number of these artefactual bands, the more difficult it is to recognise not only legitimate abnormal serum bands, but even CSF bands, which can be obscured by interference from the common bands. The choice of commercial source of ampholytes is more important than the choice of support media (for example, agarose $v$ polyacrylamide).

Reports of CSF protein analysis for clinicians must always clearly distinguish the facts from the interpretation and qualitative from quantitative results. Under "facts" it should be clear whether the band pattern in CSF is polyclonal (no bands), monoclonal (paraprotein bands), or oligoclonal (few bands). 
There must be parallel investigation of serum with a clear comment on the relative band patterns in CSF and serum. Figures 2 and 3 show examples of the five types of patterns.

The banding patterns on isoelectric focusing shown in figure 2 are simplified for purposes of demonstration. Densitometric scanning is not required for interpretation.

Figure 3 gives actual banding patterns as examples of the five types. Original patterns are always more clearly visualised than any photographic reproductions.

For the five types of band patterns, only patterns 2 and 3 represent local synthesis of IgG within the CNS. Evaluations are as follows: (1) normal CSF; (2) CSF restricted oligoclonal bands: local synthesis; (3) CSF restricted oligoclonal bands with additional, identical bands in CSF and serum: local synthesis; (4) identical oligoclonal bands in CSF and serum: not local synthesis; (5) monoclonal bands in CSF and serum: not local synthesis.

IgA

IgA analysis, either by quantitative or qualitative techniques, is of little value for the laboratory supported diagnosis of multiple sclerosis.

Strong intrathecal IgA production, however, may imply a different diagnosis. Most methods for quantitative analysis of IgA production have so far failed to take into account the relative proportion of monomeric and dimeric IgA in both CSF and serum, although dimeric IgA was shown to be preferentially produced in cases of intrathecal synthesis. ${ }^{40}$ As a consequence, amounts of local IgA synthesis could be underestimated depending on the method used. The occurrence of oligoclonal IgA bands on isoelectric focusing in multiple sclerosis or other neurological diseases is uncommon. ${ }^{3941}$

\section{IgM}

Determination of CSF IgM by quantitative and qualitative methods to show intrathecal production of IgM are optional tests for the diagnosis of multiple sclerosis. The recommended method for qualitative detection of oligoclonal IgM bands is electrophoresis or isoelectric focusing of unconcentrated CSF and subsequent immunodetection. ${ }^{42}$ Intrathecal production has been found, by quantitative and qualitative assays, in only $30 \%$ to $60 \%$ of patients with multiple sclerosis and thus seems to be of less value than detection of oligoclonal IgG bands. A degree of clinical relevance of $\operatorname{IgM}$ estimation has been reported due to its decrease with duration of the disease process ${ }^{43}$ and conversely, being more common with early exacerbations of the disease. ${ }^{44} 45$

Further collaborative work is required to ascertain correlations between clinical variables and other CSF indices including myelin basic protein..$^{29} 46$

FREE LIGHT CHAINS

In multiple sclerosis, oligoclonal free light chain bands are seen with about the same frequency as that for oligoclonal IgG bands, and this detection is a complementary, although optional, test to establish a laboratory supported diagnosis. ${ }^{27}$ Electrophoresis on polyacrylamide gel $^{47}$ or agarose ${ }^{48}$ are alternative techniques that can be used to separate free from bound light chains. After separation, free light chains are identified by immunostaining.

The quantitative determination of free light chains is critically dependent on the specificity of the antiserum used. ${ }^{49}$ Absolute levels of free $\kappa$ and $\lambda$ light chains are increased in about $80 \%$ and $60 \%$ of multiple sclerosis samples respectively. ${ }^{44}$ The influence of both the serum concentrations and of the brainCSF barrier on the CSF concentrations are taken into account by the calculation of index values. ${ }^{49}$

\section{QUALITY ASSURANCE}

Most of the standards for analytes in diagnosis from CSF are defined as method related values. For internal quality assurance it is necessary to use a reference material such as diluted serum or, much better, an accepted CSF control sample. For detection of precision a local CSF pool can be used as a daily control. External quality assessment (CSF survey) by an external agency is also necessary. The international standardising organisations have cooperated to develop a harmonised proficiency testing protocol for CSF.

Analysis of CSF has the advantage that a $\mathrm{CSF} / \mathrm{serum}$ quotient can be calculated for each protein. If CSF and serum protein values are measured in the same run, the quotient eliminates many of the discrepancies due to method related calibrations. The $\mathrm{CSF} / \mathrm{serum}$ quotient thus approximates to a method independent value.

The problem of a complicated quality control in cytology could be solved by sending sets of cytological slide preparations to different laboratories.

Proficiency testing in CSF analysis should also consider the control of the quality of data interpretation by including the five different focusing patterns ${ }^{50}$ that have been widely recognised in our collaborative studies of "blind" CSF samples (data not shown).

\section{costs}

The costs vary from around $£ 25$ to $£ 90$ per profile for the four tests listed in table 1 . There seem to be three major variables that contribute to these costs: (1) technician time: beyond the basic costs for various labour intensive techniques, there may even be on call payments - for example, in the case of cell counting; (2) reagents: these are divided mainly between the more expensive commercial preparations that are available for the various tests as opposed to the much more economical "home-brewed" reagent kits; (3) interpretation: this depends largely on the analyst having the necessary degree of experience required to recognise the five basic patterns. 
1 Poser CM, Paty DW, Scheinberg L, et al. New diagnostic criteria for multiple sclerosis: Guidelines for research protocols. Ann Neurol 1983;13:227-31.

2 Bradbury $M$. The concept of a blood-brain barrier. Chichester; John Wiley and Sons, 1979.

3 Fishman RA. Cerebrospinal fluid in diseases of the nervous system. 2nd ed. Philadelphia: WB Saunders and $\mathrm{Co}$ 1992.

4 Kostulas VK. Oligoclonal IgG bands in cerebrospinal fluid. Acta Neurol Scand (suppl 103) 1985;72:1-112.

$5 \mathrm{Link} \mathrm{H}$. The cerebrospinal fluid in multiple sclerosis. In Swash M, Oxbury J, eds. Clinical neurology. Edinburgh Churchill Livingstone, 1991:1128-39.

6 Reiber H. Liquorprotein diagnostik. In: Thomas L, FatehMoghadam A, Guder WS, Hofmann W, Reiber $H$, Lammers $M$, eds. Proteindiagnostik. Frankfurt: Behringwerke AG, 1991:140-67 (also translated into Italian).

7 Schuller E. A new strategy for the study of intrathecal immunity. In: Marrosu MG, Cianchetti C, Tavolato B. eds. Trends in neuroimmunology. New York: Plenum Press, 1990:3-12.

8 Thompson EJ. The CSF proteins: a biochemical approach Amsterdam: Elsevier, 1988

9 Tourtellotte WW. The cerebrospinal fluid in multiple sclerosis. In: Vinken PJ, Bruyn GW, Klawans HS, eds. Handbook of clinical neurology. Amsterdam: Elsevier, 1985:79-130

10 Meena CE, Olson WH, Yam LT. Light microscopic cytology of cerebrospinal fluid. In: Herndon RM, Brumback RA, eds. The cerebrospinal fluid. Boston Kluwer Academic Publishers, 1989:227-44.

11 Felgenhauer $K$. Protein size and cerebrospinal fluid composition. Klin Wochenschr 1974;52:1158-64.

12 Tourtellotte WW, Potvin AR, Fleming JO, et al. Multiple sclerosis: measurement and validation of central nervous system IgG synthesis rate. Neurology 1980;30:240-4.

13 Schuller EAC, Benabdallah S, Sagar HJ, Reboul JAM, Tömpe LC. IgG synthesis within the central nervous system. Arch Neurol 1987;44:600-4.

14 Schuller E, Sagar HJ. Local synthesis of CSF immunoglobulins. $\mathcal{F}$ Neurol Sci 1981;51:361-70.

15 Tibbling G, Link H, Öhman S. Principles of albumin and IgG analyses in neurological disorders. 1. Establishmen of reference values. Scand $\mathcal{f}$ Clin Lab Invest 1977;37 385-90.

16 Blennow K, Fredman P, Wallin A, et al. Protein analyse in cerebrospinal fluid. II. Reference values derived from healthy individuals 18-88 years of age. Eur Neurol 1993 33:129-33.

17 Link H, Tibbling G. Principles of albumin and IgG analysis in neurological disorders: III. Evaluation of IgG synthesis within the central nervous system in multiple sclerosis. Scand $\mathcal{F}$ Clin Lab Invest 1977;37:397-401.

18 Lolli F, Halawa I, Link H. Intrathecal synthesis of IgG, IgA, IgM and IgD in untreated multiple sclerosis and controls. Acta Neurol Scand 1989;80:238-47.

19 Reiber H, Felgenhauer K. Protein transfer at the blood cerebrospinal fluid barrier and the quantitation of the humoral immune response within the central nervous system. Clin Chim Acta 1987;163:319-28.

20 Laurell C-B. On the origin of major CSF proteins. In: Thompson EJ, ed. Advances in CSF protein research and diagnosis. Lancaster: MTP Press Ltd, England. 1987 123-8.

21 Luxton RW, McLean BN, Thompson EJ. Isoelectric focusing versus quantitative measurements in the detection of intrathecal local synthesis of IgG. Clin Chim Acta 1990;187:297-308

22 Öhman S, Ernerudh J, Forsberg P, Henriksson A, von Schenk H, Vrethem M. Comparison of seven formulae and isoelectrofocusing for determination of intrathecally produced IgG in neurological disease. Ann Clin Biochem 1992;29:405-10.

23 Felgenhauer K, Schädlich H-J. The compartmental IgM and IgA response within the central nervous system. $f$ and IgA response within the

24 Felgenhauer $K$, Reiber $H$. The diagnostic relevance of antibody specificity indices in multiple sclerosis and herpes virus induced diseases of the nervous system. Clin Invest 1992;70:28-37.

25 Felgenhauer K, Schädlich H-J, Nekic M, Ackermann R. Cerebrospinal fluid virus antibodies. A diagnostic indicator for multiple sclerosis? ₹ Neurol Sci 1985;71:291-9.

26 Reiber H, Lange P. Quantitation of virus-specific antibody concentration in cerebrospinal fluid and serum: sensitive and specific detection of antibody synthesis in brain. Clin Chem 1991;37:1153-60.

27 Sindic CJM, Laterre EC. Oligoclonal free kappa and lambda bands in the cerebrospinal fluid of patients with MS and CNS infections. An immunoaffinity-mediated capillary blot study. $\mathcal{F}$ Neuroimmunol 1991;33:63-72.

28 Luxton RW, Thompson EJ. Affinity distributions of antigen-specific IgG in patients with multiple sclerosis and gen-specific IgG in patients with multiple sclerosis and
in patients with viral encephalitis. $f$ Immunol Method
1990;13:277-82.

29 Frequin STFM, Barkhof F, Lamers KJB, Hommes OR, Borm GF. CSF myelin basic protein, IgG and IgM levels in 101 MS patients before and after treatment with high-dose intravenous methylprednisolone. Acta Neurol Scand 1992;86:291-7.

30 Gallo $P$, Tavolato B, Bergenbrant S, Siden A. Immunoglobulin light chain patterns in the cerebrospinal fluid. A study with special reference to the occurrence of free light chains in cerebrospinal fluid with and without oligoclonal immunoglobulin G. $f$ Neurol Sci 1989;94:241-53.

31 Livrea P, Trojano M, Simone IL, Zimatore GB, Lamontanara G. Intrathecal IgG synthesis in multiple sclerosis: comparison between isoelectric focusing and quantitative estimation of cerebrospinal fluid IgG. $\mathcal{F}$ Neurol 1981;224:159-69.

32 Nespolo A, Bianchi G, Salmaggi A, Lazzaroni M, Cerrato D, Tajoli LM. Immunoblotting techniques with picogram sensitivity in cerebrospinal fluid protein detecpicogram sensitivity in cerebrospinal

33 Olsson T, Kostulas V, Link H. Improved detection of oligoclonal IgG in cerebrospinal fluid by isoelectric focusing in agarose, double-antibody peroxidase labelling, and avidin-biotin amplification. Clin Chem 1984;30:409-21.

34 Souverijn JHM, Serrée HMP, Peet R, Grenzebach Smit W, Bruyn GW. Intrathecal immunoglobulin synthesis. Comparison of various formulae with the "gold standard" of isoelectric focussing. F Neurol Sci 1991 102:11-6

35 Staugaitis SM, Shapack P, Tourtellotte WW, Lee MM, Reiber H-O. Isoelectric focusing of unconcentrated cerebrospinal fluid: applications to ultrasensitive analysis of oligoclonal immunoglobulin G. Electrophoresis 1985;6:287-91.

36 Walker RWH, Keir G, Johnson MH, Thompson EJ. A rapid method for detecting oligoclonal IgG in unconcentrated CSF by agarose isoelectric focusing, transfer to cellulose nitrate and immunoperoxidase staining. $\mathcal{F}$ Neuroimmunol 1983;4:141-8.

37 Wikkelsö C, Andersson M, Andersson R, Blomstrand C. Isoelectric focusing followed by silver staining: a suitable method for routine investigation of cerebrospinal fluid proteins. Eur Neurol 1984;23:306-12.

38 Wurster U. Demonstration of oligoclonal IgG in the unconcentrated CSF by silver stain. In: Stathakos D ed. Electrophoresis '82. Berlin: Walter de Gruyter and Co, 1983:250-9.

39 Martino G, Servalli C, Filippi M, et al. Absence of oligoclonally restricted immunoglobulins in tears from multiple sclerosis patients. I Neuroimmunol 1993;4: 149-56.

40 Sindic CIM, Delacroix DL, Vaerman JP, Laterre EC Masson PL. Study of IgA in the cerebrospinal fluid of neurological patients with special reference to size, subclass and local production. $₹$ Neuroimmunol 1984;7: class a

41 Mehta PD, Patrick BA, Miller JA. Absence of oligoclonal IgA in CSF and serum of multiple sclerosis patients. $f$ Neuroimmunol 1984:6:67-9.

42 Sharief MK, Thompson EJ. Distribution of cerebrospinal fluid oligoclonal IgM bands in neurological diseases: a comparison between agarose electrophoresis and isoelectric focusing. $\mathcal{F}$ Neurol Sci 1992;109:83-7.

43 Sharief MK, Thompson EJ. Intrathecal immunoglobulin M synthesis in multiple sclerosis. Brain 1991;114 181-95.

44 Lolli F, Siracusa G, Amato MP, et al. Intrathecal synthesis of free immunoglobulin light chains and $\mathrm{IgM}$ in initial multiple sclerosis. Acta Neurol Scand 1991;83:239-43.

45 Sharief MK, Thompson EJ. The predictive value of intrathecal immunoglobulin synthesis and magnetic resonance imaging in acute isolated syndromes for subsequent development of multiple sclerosis. Ann subsequent development

46 Massaro AR, Scivoletto G, Tonali P. Cerebrospinal fluid markers in neurological disorders. Ital F Neurol Sci 1990 11:537-47.

47 Vakaet A, Thompson EJ. Free light chains in cerebrospinal fluid: an indicator of recent immunological stimulation. $f$ Neurol Neurosurg Psychiatry 1985;48: 995-8.

48 Vandvik B. Oligoclonal IgG and free light chains in the cerebrospinal fluid of patients with multiple sclerosis and infectious diseases of the central nervous system. Scand F Immunol 1977;6:913-22.

49 Fagnart OC, Sindic CJM, Laterre C. Free kappa and lambda light chain levels in the cerebrospinal fluid of patients with multiple sclerosis and other neurological diseases. F Neuroimmunol 1988;19:119-32.

50 Keir G, Luxton RW, Thompson EJ. Isoelectric focusing of cerebrospinal fluid immunoglobulin G: an annotated update. Ann Clin Biochem 1990;27:436-43. 


\section{LETTER}

\section{Minor head injury: do you get what you expect?}

Having read the study of Whittaker et $a l^{1}$ concerning expectations and beliefs as predictors of recovery from minor head injury, one appreciates that this is an exciting time in the epidemiological research of these types of disorders. That is, minor head injury, whiplash injury, low back pain and related controversial disorders associated with chronic pain and disability have long been approached with a biopsychosocial model. Furthermore, although more and more studies, especially in the area of whiplash, reveal that the bio component is the least relevant, the ongoing problem has been to determine where to look for the psychosocial component. The common and fertile ground for all these disorders appears to be patient-held beliefs and, as an aspect of those beliefs, their expectations. In a longitudinal cohort study of patients with minor head injury, Whittaker et al found that patients who believe that their symptoms have serious negative consequences on their lives and will continue to do so are at heightened risk of experiencing significant enduring postconcussional symptoms. Notably, severity of the postconcussion symptoms in the initial postinjury period was not an independent predictor of outcome. Instead, the interpretation of their symptoms as serious and enduring is what puts patients at risk for chronic symptoms.

Parallel results have been found in other disorders. For individuals with whiplash injury, for example, in a population-based cohort of $>6000$ participants, after adjusting for the effect of sociodemographic characteristics, postcrash symptoms and pain, previous health status and collision-related factors, those who expected to get better soon recovered more than three times as quickly (hazard rate ratio 3.62 ; 95\% confidence interval 2.55 to 5.13 ) as those who expected that they would never get better. ${ }^{2}$ Findings were similar for resolution of painrelated limitations and resolution of neckpain intensity. In brief, controlling for initial pain, symptoms, sex, age and numerous other baseline variables, the answer to the single question early after injury "Do you think that your injury will get better soon; get better slowly; never get better; or don't know?" is a stronger predictor of recovery rate than any psychosocial variable we have ever investigated in whiplash cohorts. Expectations and beliefs also predict the likelihood of returning to work after whiplash injury ${ }^{3}$ and predict chronicity after low back injury. ${ }^{4-8}$

What is most interesting and concerning about expectations and beliefs that predict these outcomes is that these expectations and beliefs are highly prevalent in the general population, even in those who have not experienced the disorders before. It has been shown, for example, that negative beliefs about neck pain, upper extremity injury and whiplash injury, in particular, are common in a Canadian population. ${ }^{9}$ As well, among Canadian participants who have themselves not experienced a minor head injury nor have an immediate family member who has had this injury, $50 \%$ expect that chronic symptoms should follow the injury. ${ }^{10}$

The relevance of this area of research is further highlighted by the observation that in countries where a minor head injury has a much better prognosis than in, say, Western countries, these expectations are uncommon or rare. ${ }^{11} 12$ Whittaker et al are conducting research on minor head injury in the direction it needs to go if we are ever to build a model accurate enough to plan interventions that will prevent patients from getting what they expect.

Moreover, Whittaker et al provide clues to preventive interventions that may improve outcomes and considerably reduce healthcare costs in a range of disorders that are common and costly. Negative beliefs and expectations for common conditions such as minor head injury, low back pain and whiplash injury are highly prevalent and also very expensive. In Australia, approximately US $\$ 10$ million was spent on a social marketing campaign designed to alter the population beliefs about low back pain. The program was effective, and it was cost-effective, with improvements in both population and healthcare provider beliefs about back pain observed after the campaign, along with dramatic reductions in work-related disability and healthcare visits. ${ }^{13-16}$

\section{R Ferrari}

Correspondence to Robert Ferrari, University of Alberta, 4000 Research Transition Facility, 8308-114 Street, University of Alberta, Edmonton AB T6G 2V2, Canada; rferrari@shaw.ca

\section{Competing interests None.}

Provenance and peer review Not commissioned; not externally peer reviewed.

Received 26 March 2010

Accepted 1 April 2010

Published Online First 14 August 2010

J Neurol Neurosurg Psychiatry 2011:82:826. doi:10.1136/jnnp.2010.213520

\section{REFERENCES}

1. Whittaker R, Kemp S, House A. Illness perceptions and outcome in mild head injury: a longitudinal study. J Neurol Neurosurg Psychiatry 2007;78:644-6.

2. Carroll LJ, Holm L, Ferrari R, et al. Recovery in whiplash-associated disorders: do you get what you expect? J Rheumatol 2009;36:1063-70.

3. Ozegovic D, Carroll LJ, David Cassidy J. Does expecting mean achieving? The association between expecting to return to work and recovery in whiplash associated disorders: a population-based prospective cohort study. Eur Spine J 2009;18:893-9.

4. Crooks J, Milner R, Schultz IZ, et al. Determinants of occupational disability following a low back injury: a critical review of the literature. J Occup Rehabil 2002;12:277-95

5. Linton SJ. A review of psychological risk factors in back and neck pain. Spine 2000;25:1148-56.

6. Sullivan MJ, Stanish W, Waite H, et al. Catastrophizing, pain, and disability in patients with soft-tissue injuries. Pain 1998;77:253-60.

7. Sullivan MJ, Rodgers WM, Kirsch I. Catastrophizing depression and expectancies for pain and emotional distress. Pain 2001;91:147-54.

8. Truchon M, Fillion L. Biopsychosocial determinants of chronic disability and low-back pain: a review. J Occup Rehabil 2000;10:117-42.

9. Bostick GP, Ferrari R, Carroll LJ, et al. A populationbased survey of beliefs about neck pain from whiplash injury, work-related neck pain, and workrelated upper extremity pain. Eur J Pain 2009;13:300-4

10. Ferrari R, Lang CGJ. Symptom expectation for minor head injury in Canada versus Germany. Clin Neurol Neurosurg 2003;105:146-7.

11. Mickeviciene D, Schrader H, Obelieniene D, et al. A controlled prospective inception cohort study on the post-concussion syndrome outside the medicolegal context. Eur J Neurol 2004;11:411-19.

12. Ferrari R, Obelieniene D, Russell AS, et al. Symptom expectation after minor head injury. A comparative study between Canada and Lithuania. Clin Neurol Neurosurg 2001;103:184-90.

13. Buchbinder R, Jolley D. Population based intervention to change back pain beliefs: three year follow up population survey. BMJ 2004;328:321.

14. Buchbinder R, Jolley D, Wyatt M. Population based intervention to change back pain beliefs and disability: three part evaluation. BMJ 2001;322:1516-20.

15. Buchbinder R, Jolley D, Wyatt M. 2001 Volvo award winner in clinical studies: effects of a media campaign on back pain beliefs and its potential influence on management of low back pain in general practice. Spine 2001;26:2535-42.

16. Buchbinder $\mathbf{R}$, Jolley D. Effects of a media campaign on back beliefs is sustained 3 years after its cessation. Spine 2005;30:1323-30.

\section{CORRECTIONS}

doi:10.1136/jnnp.57.8.897corr1

Andersson M, Alvarez-Cermeño J, Bernardi $G$, et al. Cerebrospinal fluid in the diagnosis of multiple sclerosis: a consensus report (J Neurol Neurosurg Psychiatry 1994;57: 897-902). The last ten authors were missing from the online version of this paper. This omission has been rectified and the authors are now all credited.

doi:10.1136/jnnp.2010.226340.63corr1

ABN Abstracts (J Neurol Neurosurg Psychiatry 2010;81:e33. doi:10.1136/jnnp.2010. 226340.63), PAW35 Anti-prion protein monoclonal antibodies at low doses effectively treat prion disease in mice without side-effects. In this abstract the author order was incorrect, it should be C Carswell, R Drynda, S Martins, A Clarke, S Brandner, S Mead, J Collinge, A Khalili-Shirazi. Also the corresponding author is j.collinge@prions. ucl.ac.uk. 